\title{
Stimulation of Neonatal and Adult Brain Neurogenesis by Subcutaneous Injection of Basic Fibroblast Growth Factor
}

\author{
Joseph P. Wagner, ${ }^{1}$ Ira B. Black, ${ }^{1}$ and Emanuel DiCicco-Bloom ${ }^{1,2}$ \\ Departments of ${ }^{1}$ Neuroscience and Cell Biology and ${ }^{2}$ Pediatrics, University of Medicine and Dentistry of New \\ Jersey/Robert Wood Johnson Medical School, Piscataway, New Jersey 08854
}

\begin{abstract}
Mounting evidence indicates that extracellular factors exert proliferative effects on neurogenetic precursors in vivo. Recently we found that systemic levels of basic fibroblast growth factor (bFGF) regulate neurogenesis in the brain of newborn rats, with factors apparently crossing the blood-brain barrier (BBB) to stimulate mitosis. To determine whether peripheral bFGF affects proliferation during adulthood, we focused on regions in which neurogenesis persists into maturity, the hippocampus and the forebrain subventricular zone (SVZ). In postnatal day 1 (P1) rats, $8 \mathrm{hr}$ after subcutaneous injection $(5 \mathrm{ng} / \mathrm{gm}$ body weight), bFGF increased $\left[{ }^{3} \mathrm{H}\right]$ thymidine incorporation $70 \%$ in hippocampal and SVZ homogenates and elicited twofold increases in mitotic nuclei in the dentate gyrus and the dorsolateral SVZ, detected by bromodeoxyuridine immunohistochemistry. Because $\sim 25 \%$ of proliferating hippocampal cells stimulated in vivo expressed neuronal traits in culture, bFGFinduced mitosis may reflect increased neurogenesis. bFGF effects were not restricted to the perinatal period; hippocampal
\end{abstract}

DNA synthesis was stimulated by peripheral factor in older animals (P7-P21), indicating the persistence of bFGFresponsive cells and activity of peripheral bFGF into late development. To begin defining underlying mechanisms, pharmacokinetic studies were performed in P28 rats; bFGF transferred from plasma to CSF rapidly, levels rising in both compartments in parallel, indicating that peripheral factor crosses the BBB during maturity. Consequently, we tested bFGF in adults; peripheral bFGF increased the number of mitotic nuclei threefold in the SVZ and olfactory tract, regions exhibiting persistent neurogenesis. Our observations suggest that bFGF regulates ongoing neurogenesis via a unique, endocrine-like pathway, potentially coordinating neuron number and body growth, and potentially providing new approaches for treating damaged brain during development and adulthood.

Key words: hippocampus; subventricular zone; basic fibroblast growth factor; subcutaneous injection; neurogenesis; in vivo neural stem cells
Proper functioning of neural systems requires coordinating neuronal numbers to target cell requirements. Traditionally, control of neuron number has been considered a late developmental process; after production of "excess" cells during neurogenesis, targets "select" neurons for survival from postmitotic pools by providing limiting trophic support (Purves, 1988; Oppenheim, 1991). Target tissues and their growth factors had no apparent effects on precursor proliferation in classical studies (Prestige, 1967; Hollyday and Hamburger, 1976; Carr and Simpson, 1978), leading to the perception that neurogenesis was unresponsive to environmental signals.

In contrast, extensive studies in culture suggest that extracellular factors critically regulate proliferation (Gensburger et al., 1987; DiCicco-Bloom and Black, 1988, 1989; DiCicco-Bloom et al., 1990; Pincus et al., 1990; Gao et al., 1991; Ray et al., 1993). Growth factors not only increase the fraction of cells engaged in the cell cycle, a traditional mitogenic function, but also enhance

Received Dec. 2, 1998; revised April 13, 1999; accepted April 28, 1999.

This work was supported by National Institutes of Health Grant HD23315 (E.D.-B. and I.B.B.). E.D.-B. and I.B.B. are members of the Cancer Institute of New Jersey. We thank Drs. Yong Tao and Evan Wolf for insightful discussions and Feng $\mathrm{Cai}$ and Xiaofeng Zhou for excellent technical and computer support. We thank Scios (Mountain View, CA) for providing recombinant human bFGF.

Correspondence should be addressed to Dr. Emanuel DiCicco-Bloom, Department of Neuroscience and Cell Biology, University of Medicine and Dentistry of New Jersey/Robert Wood Johnson Medical School, 675 Hoes Lane, Room 338 CABM, Piscataway, NJ 08854.

Dr. Wagner's present address: Department of Medical Biochemistry and Biophysics, Laboratory of Molecular Neurobiology, Karolinska Institute, Doktorsringen 12A, Stockholm 171 77, Sweden.

Copyright (C) 1999 Society for Neuroscience 0270-6474/99/196006-11\$05.00/0 survival of dividing precursors that otherwise undergo naturally occurring cell death (Drago et al., 1991; DiCicco-Bloom et al., 1993; Pincus et al., 1994; ElShamy et al., 1996; Yaginuma et al., 1996). Although proliferative effects of environmental signals are well characterized in culture, less is known about functions in vivo.

In general terms, matching neuron populations to targets consists of coordinating brain size and body growth. However, the recent identification of both neural precursors and persistent neurogenesis in the mature brain (Gould et al., 1992; Reynolds and Weiss, 1992; Richards et al., 1992; Lois and Alvarez-Buylla, 1993; Luskin, 1993; Cameron et al., 1995; Weiss et al., 1996; McKay, 1997) raises the possibility that neuronal numbers are actively synchronized throughout life. As a potential source of synchronizing signals, can target fields provide factors to regulate neurogenesis? To address this issue, we recently examined effects of basic fibroblast growth factor (bFGF) (Tao et al., 1996), because it stimulates proliferation of multiple precursors in culture (Gensburger et al., 1987; DiCicco-Bloom et al., 1990; Gao et al., 1991; Ray et al., 1993; Vicario-Abejon et al., 1995) and cognate receptors are expressed in regions undergoing neurogenesis in vivo (Wanaka et al., 1991; Fayein et al., 1992; El-Husseini et al., 1994). Peripheral injection of small doses of bFGF rapidly stimulated neurogenesis in neonatal cerebellum, increasing the proportion of mitotic granule cell precursors. Moreover, intact bFGF entered brain parenchyma to stimulate mitosis, suggesting ongoing communication between somatic tissue and neurogenetic regions (Tao et al., 1996). 
The existence of a physiological pathway transporting peripheral growth factors to neurogenetic regions has significant ontogenetic and potential therapeutic implications, especially if such mechanisms persist into adulthood. In turn, we now focus on hippocampal formation (or region) precursors and multipotential neural precursor cells in forebrain subventricular zone (SVZ), populations that continue to proliferate into maturity (Altman and Bayer, 1990; Gould et al., 1992; Morshead and van der Kooy, 1992; Lois and Alvarez-Buylla, 1993; Luskin, 1993; Kuhn et al., 1996; Weiss et al., 1996) and that respond to bFGF in vitro (Richards et al., 1992; Ray et al., 1993; Vescovi et al., 1993; Kilpatrick and Bartlett, 1995; Vicario-Abejon et al., 1995; Gritti et al., 1996). Because changes in precursor responsiveness or a maturing blood-brain barrier (BBB) could prevent central actions at older ages, we initially characterized bFGF actions in neonates and then defined activity through adulthood. Our observations indicate that subcutaneous bFGF rapidly crosses the $\mathrm{BBB}$ throughout life, regulating proliferation of neural precursors during adulthood as well as development.

\section{MATERIALS AND METHODS}

Animals and treatments. Time-mated pregnant Sprague Dawley rats (Hilltop, Scottsdale, PA) were housed individually and provided food and water ad libitum. On the day of birth, defined as $\mathrm{P} 0$, litters were culled to 10-12 pups each. To start experiments, we gave pups a subcutaneous injection ( $5 \mathrm{ng} / \mathrm{gm}$ body weight) of basic FGF (bovine pituitary; Collaborative Research, Bedford, MA) in $1 \mathrm{mg} / \mathrm{ml} \mathrm{BSA} \mathrm{in} 0.1 \mathrm{M}$ PBS. Injections were administered into the axillary subcutaneous space at a volume not exceeding $2 \mu \mathrm{l} / \mathrm{gm}$ body weight. Controls received equivalent volumes of vehicle. For higher doses of bFGF, growth factor concentration was increased, holding injection volume constant.

Six hours after bFGF or vehicle injection, rats were given one or both of two markers of DNA synthesis, thymidine [methyl $\left.-{ }^{3} \mathrm{H}\right](5 \mu \mathrm{Ci} / \mathrm{gm}$ body weight; Dupont NEN, Boston, MA) or bromodeoxyuridine (BrdU; 100 $\mu \mathrm{g} / \mathrm{gm}$ body weight; Sigma, St. Louis, MO), administered subcutaneously. Two hours later (a total of $8 \mathrm{hr}$ after bFGF injection), animals were killed by decapitation, whole brains were excised, and tissue was processed as described below.

For pharmacokinetic studies, young adult rats [postnatal day 28 (P28)] received either $500 \mathrm{ng} / \mathrm{gm}$ body weight recombinant human bFGF (in radioimmunoassay experiments; generous gift of Scios, Mountain View, $\mathrm{CA})$ or $5 \mu \mathrm{Ci}{ }^{125} \mathrm{I}-\mathrm{bFGF}(>70 \mu \mathrm{Ci} / \mu \mathrm{g} ;>1200 \mathrm{Ci} / \mathrm{mmol}$; Dupont NEN) diluted with cold recombinant human bFGF to a final dose of $20 \mathrm{ng} / \mathrm{gm}$ body weight (in radiolabel tracing experiments), injected subcutaneously. At different time intervals, animals were deeply anesthetized with pentobarbital, and a sample $(\sim 100 \mu \mathrm{l})$ of CSF was collected through a fine needle inserted into the cisterna magna; afterward, a sample of blood was obtained via cardiac puncture. Samples were immediately frozen on dry ice and stored at $-80^{\circ} \mathrm{C}$ until assay or until radioactivity was quantitated in a gamma-radioactivity counter.

Determination of $\left[{ }^{3} H\right]$ thymidine incorporation. Whole P1 brains were dissected into two regions using a dissection microscope: the hippocampal region (or formation), which was removed from overlying cortex, and the rostral forebrain, defined by blunt cuts in the coronal plane immediately rostral to the corpus striatum and caudally at the fornical junction. In adult (P60) brains, the olfactory bulb, tract, and cerebellum were also isolated. After meninges and surface blood vessels were removed, tissues were stored at $-80^{\circ} \mathrm{C}$ until use. DNA synthetic rate was evaluated using a "percent incorporation" assay. Briefly, tissues were homogenized in at least 10 volumes of distilled water, and an aliquot was removed for determination of total isotope uptake. DNA was precipitated with $10 \%$ trichloroacetic acid, sedimented by centrif ugation, and washed twice by resuspension and resedimentation, and the final pellet was dissolved and counted along with the total homogenates in a scintillation spectrometer. Radiolabel incorporation into DNA depends on the amount of label taken up by the tissue; consequently, incorporation was calculated as the fraction of total tissue uptake. Thus, experimental effects on incorporation do not result from differences in labeled precursor available but rather reflect alterations in DNA synthesis per se. However, total tissue uptake of radiolabel did not differ among groups at any age.

BrdU immunohistochemistry and quantitation. After treatment, adult animals were perfused transcardially under deep anesthesia with $4 \%$ paraformaldehyde in PBS, whereas P1 brains were fixed by immersion. Tissues were post-fixed for $24 \mathrm{hr}$, dehydrated via graded ethanols, cleared, (Histoclear; National Diagnostics, Atlanta, GA), and embedded in paraffin. Brains were sectioned coronally $(5 \mu \mathrm{m})$ in a $1: 5$ series, mounted on aminopropyltriethoxysilane-coated slides, processed for BrdU incorporation using monoclonal anti-BrdU antibody (1:50; Becton Dickinson, Rutherford, NJ), and visualized with the Vector Laboratories $\mathrm{ABC}$ immunoperoxidase kit (Burlingame, $\mathrm{CA}$ ), using diaminobenzidine intensified with nickel cobalt as reported previously (Tao et al., 1996). Sections were counterstained with $0.1 \%$ basic fuschin, dehydrated, cleared, and coverslipped with DPX mountant (Fluka, Neu-Ulm, Germany).

In P1 animals, BrdU-labeled cells were counted in the hilar region of the dentate gyrus (DG) (in sections extending from the caudal fornix to the disappearance of the DG) and in the dorsolateral corner of the forebrain SVZ (in sections extending from the anterior commissure to the most caudal portion of the genu of the corpus callosum). In adults, BrdU-labeled cells were counted in the SVZ and the anterior olfactory nucleus of the olfactory tract. Every fifth section was counted, with an average of 20 sections per region in each animal and with a minimum of three animals in each age and treatment group. Exact section numbers quantified are indicated in the figure legends. Because this approach quantitates nuclear profiles, several caveats need to be considered. Any consistent differences among groups in tissue volume, whether physiological or histological, or changes in nuclear size (or shape) or density would alter the likelihood of including a specific profile in an individual tissue section (Coggeshall and Lekan, 1996). However, it is highly unlikely that changes occurring within $8 \mathrm{hr}$ make major contributions to reported differences. Indeed, nuclear size is unaltered $8 \mathrm{hr}$ after peripheral bFGF injection (Tao et al., 1996).

Cell culture and in vitro double immunocytochemistry. P1 rats were treated with bFGF and BrdU as described above. After sacrifice, cleaned hippocampi pooled from five to six animals in each group were incubated in a $1 \%$ trypsin and $0.1 \%$ DNase solution (Worthington, Freehold, NJ) for $3 \mathrm{~min}$ and dissociated in $0.05 \%$ DNase in DMEM by trituration through graded-bore fire-polished pipettes. After pelleting, cells were filtered through $30 \mu \mathrm{m}$ nylon mesh (Tetko, Elmsford, NY), resuspended, and plated $\left(10^{5}\right.$ cells $/$ dish $)$ onto poly-D-lysine-coated $(0.1 \mathrm{mg} / \mathrm{ml}) 35 \mathrm{~mm}$ culture dishes in defined medium (DiCicco-Bloom et al., 1993; Tao et al., 1996) supplemented with $5 \%(\mathrm{v} / \mathrm{v})$ heat-inactivated fetal bovine serum. Cultured cells were incubated for $48 \mathrm{hr}$ and fixed with $4 \%$ paraformaldehyde for $30 \mathrm{~min}$ for immunocytochemistry.

To characterize the phenotype of the mitotic population, we sequentially stained cultured hippocampal cells for the cell type-specific marker and BrdU incorporation. In brief, sister cultures were incubated with one of three antibodies: mouse anti- $\beta$-tubulin class III neuron-specific isotype (clone TuJ1; 1:400; Dr. A. Frankfurter, University of Virginia, Charlottesville, VA), rabbit anti-MAP-2 (1:1000; Dr. I. Fischer, Medical College of Philadelphia, Philadelphia, PA), or rabbit anti-GFAP (1:1000; Dako, Carpinteria, CA). After washing, cultures were incubated for 1-3 hr with appropriate secondary antibodies (1:100; Texas Red-conjugated horse anti-mouse or goat anti-rabbit; Vector Laboratories). Cultures were post-fixed in $4 \%$ paraformaldehyde and processed for $\mathrm{BrdU}$ as described above, except that no trypsin incubation was performed and BrdU immunoreactivity was visualized using a FITC-conjugated secondary antibody (1:200; Vector Laboratories). This order of staining resulted in little to no cross-reactivity between either primary or secondary antibodies, determined by appropriate control procedures (e.g., leaving out either primary antibody or Texas Red secondary). Single- and double-fluorescent populations were collected from at least $100 \mathrm{BrdU}$ positive cells counted in each of four dishes in each treatment group obtained from two independent experiments, using a Leitz dualfluorescence microscope (Wetzlar, Germany) at $400 \times$ magnification.

$b F G F$ radioimmunoassay. bFGF levels were assayed in CSF and plasma using a radioimmunoassay technique. In brief, triplicate experimental samples were incubated with $0.01 \mu \mathrm{Ci}$ of ${ }^{125} \mathrm{I}$-bFGF (Dupont $\mathrm{NEN}$ ) and $0.075 \mu \mathrm{g}$ of polyclonal anti-bFGF antibody (R \& D Systems, Minneapolis, MN) in a total volume of $300 \mu$ l of PBS with $2 \mathrm{mg} / \mathrm{ml} \mathrm{BSA}$ overnight at $4^{\circ}$. The bound fraction was collected by incubating samples with an equal volume of $1 \%(\mathrm{w} / \mathrm{v})$ protein-A-conjugated Sepharose beads (Pharmacia, Piscataway, NJ) for $2 \mathrm{hr}$ at room temperature with agitation. The beads were then pelleted and washed, and radioactivity was quantitated. A standard curve was generated in parallel, using a 1:1 dilution series of bFGF, from $6.25 \mathrm{pg}$ to $12.8 \mathrm{ng}$ per tube. The standard 


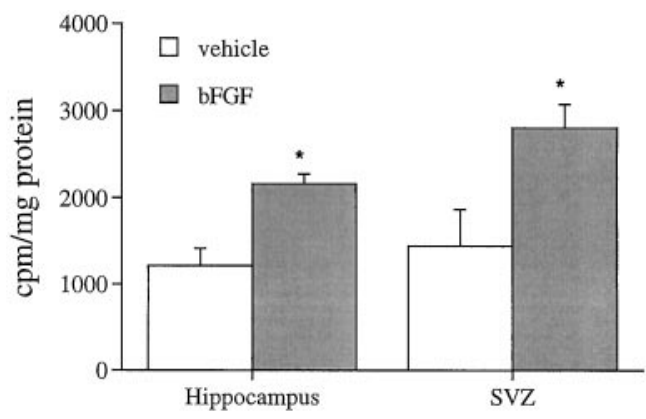

Figure 1. Effects of peripheral treatment with bFGF on $\left[{ }^{3} \mathrm{H}\right]$ thymidine incorporation in the hippocampal region and the forebrain SVZ on P1. After subcutaneous injection of bFGF ( $5 \mathrm{ng} / \mathrm{gm}$ body weight) at zero time and $\left[{ }^{3} \mathrm{H}\right]$ thymidine $(5 \mu \mathrm{Ci} / \mathrm{gm})$ at $6 \mathrm{hr}$, brain regions were analyzed at 8 $\mathrm{hr}$ for thymidine incorporation. Data represent mean incorporation $(\mathrm{cpm})$ + SEM in tissues obtained from three to four animals in each of two experiments. Results of two-way ANOVA (factors of treatment and region) indicate a global $90 \%$ elevation in DNA synthesis in response to bFGF $\left({ }^{*} p<0.0002\right)$; this increase was equivalent in both regions (i.e., no treatment $\times$ region interaction).

curve was linearly fitted, with an average detection limit of $\sim 10 \mathrm{pg} /$ tube. Specificity of the assay was verified by incubating samples with excess amounts of acidic (a)FGF, FGF-4, -6, or keratinocyte growth factor; none of these affected assay sensitivity.

Data analysis. Data are reported as means and SEM. For each variable, initial statistical comparisons were performed by a global ANOVA, with the multiple factors of treatment (vehicle vs bFGF) and region, age, anatomical gradient, and/or dose; if significant interactions between treatment and any other variable existed, data were further divided into separate regions, ages, anatomical zones, or dose groups. Fisher's protected least significant difference was used post hoc to identify specific points at which the bFGF group differed from controls only when significant interactions between factor treatment and other variables (region, dose, etc.) occurred. Significance for all tests was assumed at the level of $p<0.05$. To simplify presentation in the Results, the outcome of individual statistical analyses, as well as the actual analysis performed in each experiment, is presented within individual figure legends. Occasionally, for ease of presentation, data are expressed as "percent control"; however all statistical analysis and post hoc testing were performed on unmanipulated data.

\section{RESULTS}

\section{Mitogenic effects of peripheral bFGF on P1}

To examine potential mitogenic effects of peripheral bFGF in neurogenetic populations of neonatal rostral forebrain and hippocampal formation (or region), we measured DNA synthesis in whole-tissue homogenates (Fig. 1), a previously characterized and convenient technique for screening mitogens in vivo (Tao et al., 1996). Subcutaneously administered bFGF stimulated $\left[{ }^{3} \mathrm{H}\right]$ thymidine $\left(\left[{ }^{3} \mathrm{H}\right] \mathrm{dT}\right)$ incorporation $80-90 \%$ in both regions, suggesting that the factor enhanced ongoing proliferation. To localize and quantify the responsive populations, we identified cells in S-phase of the mitotic cycle, using BrdU immunohistochemistry. Peripheral bFGF elicited approximately twofold increases in the number of mitotic cells in the hippocampal region and rostral forebrain, with major effects restricted to discrete anatomical areas.

In the hippocampal formation, bFGF-responsive cells were located throughout the hilus of the dentate gyrus (Fig. $2 A, B$ ), a well characterized neurogenetic region in the newborn generating dentate granule neurons (Altman and Bayer, 1990). To determine the magnitude and potential selectivity of bFGF action, we compared the number of mitotic nuclei in the neurogenetic hilus with that in the non-neurogenetic stratum radiatum (Fig. $3 A$ ). bFGF treatment nearly doubled the number of mitotic cells in the hilus; this increase was observed across the entire rostrocaudal length of the hippocampal formation, with a peak, twofold response in a zone $1.0-1.6 \mathrm{~mm}$ caudal to the fornical juncture (Fig. $3 C$ ). In contrast, only slight increases in mitotic cells occurred in the caudal third of the stratum radiatum (Fig. 3D), suggesting that peripheral bFGF stimulated neurogenesis in selected regions of the hippocampal formation.

Within the rostral forebrain, peripheral bFGF stimulated mitosis in the dorsolateral corner of the SVZ (Figs. 2C,D, 3B), a previously characterized source of multipotential precursors that is easily defined across gradients of anatomy and age (Morshead and van der Kooy, 1992; Lois and Alvarez-Buylla, 1993, 1994; Luskin, 1993; Vescovi et al., 1993; Gritti et al., 1996). Peripheral bFGF stimulated mitosis by $50-150 \%$ within this population, determined by quantitative analysis (Fig. $3 E$ ), suggesting that the factor stimulates division in precursors of both neurons and glia.

\section{In vitro analysis of bFGF-responsive populations in the hippocampal region}

To begin defining the potential fates of bFGF-responsive cells, we examined phenotypic characteristics of hippocampal region precursors stimulated in vivo in culture. After growth factor and the mitotic marker BrdU were administered in vivo, hippocampal cells were isolated and incubated in culture for $48 \mathrm{hr}$. Consistent with brain tissue immunohistochemistry, peripheral bFGF treatment in vivo doubled the number of BrdU-labeled cells observed in culture (see Fig. 5A). BrdU-labeled precursors exhibited a variety of phenotypic markers (Fig. 4); approximately one-third of the cells expressed neuronal markers, including neuron-specific $\beta$-tubulin III (TuJ1; 31\%) and MAP-2 (20\%), whereas onequarter exhibited the astrocytic marker GFAP (Fig. 5B). The remainder of BrdU-positive cells (45\%) exhibited morphologies consistent with macrophages or fibroblasts (data not shown). Although in vivo bFGF treatment increased the proportion of BrdU-positive cells detected in culture, the frequency of phenotypic markers was unaffected by factor treatment, suggesting that bFGF can stimulate production of both neurons and astrocytes in vivo.

\section{Effects of peripheral bFGF on hippocampal region mitosis during later development}

The robust effects of peripheral bFGF on neurogenesis in neonates encouraged us to investigate possible activity of the factor in adults. However, a number of variables might limit activity of peripherally administered factor in older animals. Developmental changes in the peripheral metabolism of bFGF or exclusion from the CNS by a maturing $\mathrm{BBB}$ might reduce or eliminate bFGF effectiveness. Alternatively, changes in the dynamics of responsive populations, including decreased size or increases in cell cycle length, might also limit responsiveness. To explore these possibilities, we administered the same subcutaneous dose of bFGF (5 ng/gm body weight) to P1, P7, P14, and P21 rats and assessed hippocampal region DNA synthesis. To allow comparison among ages in which baseline values differ significantly, we assessed DNA synthesis using a percent incorporation assay, which normalizes $\left[{ }^{3} \mathrm{H}\right] \mathrm{dT}$ incorporation to total tissue uptake (see Materials and Methods). Indeed, basal DNA synthetic rate rapidly decreased with age [reflecting cessation of hippocampal region cell division (Kuhn et al., 1996)]. However, bFGF continued to elicit $25-30 \%$ increases in $\left[{ }^{3} \mathrm{H}\right] \mathrm{dT}$ incorporation on P7- 


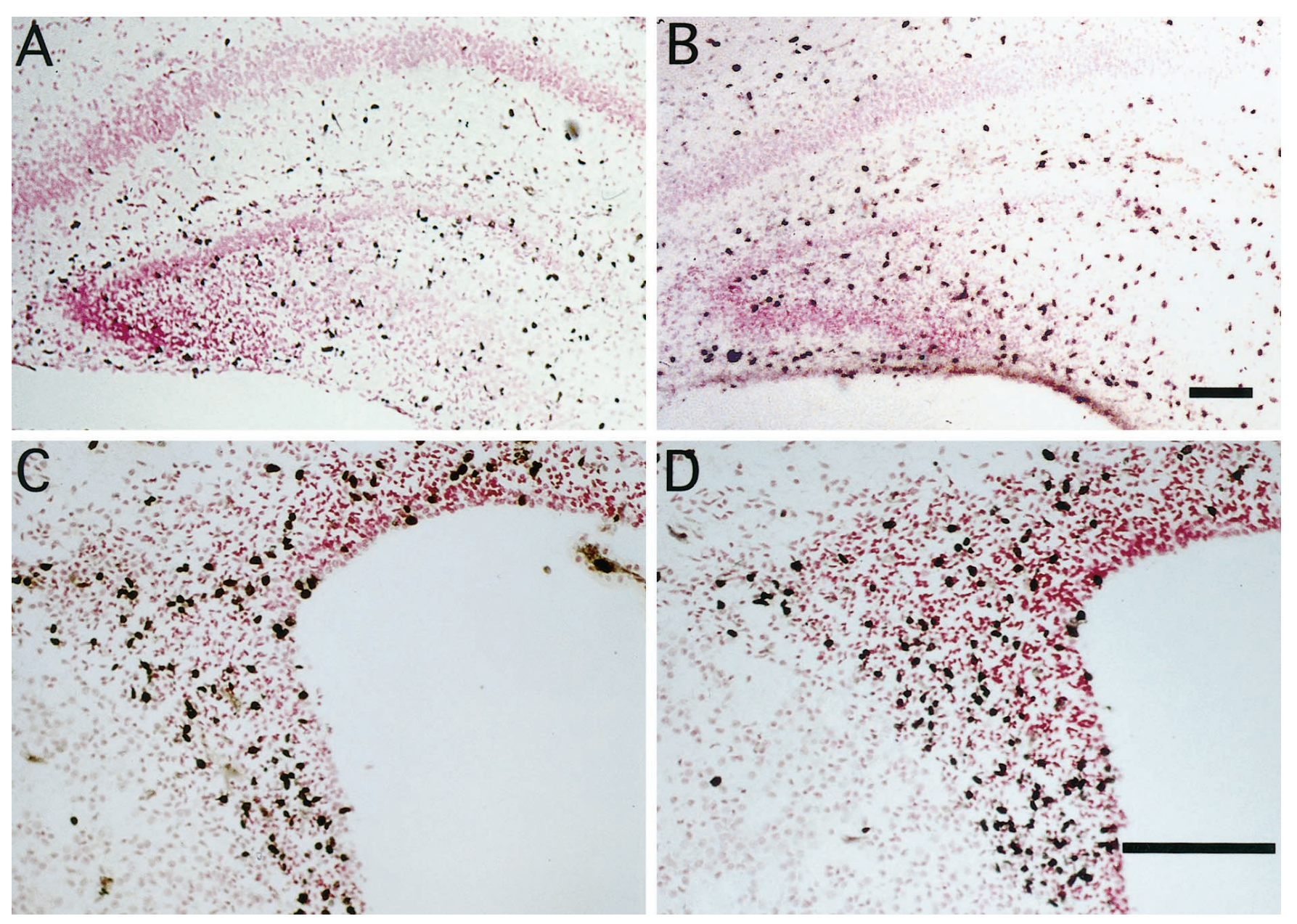

TuJI
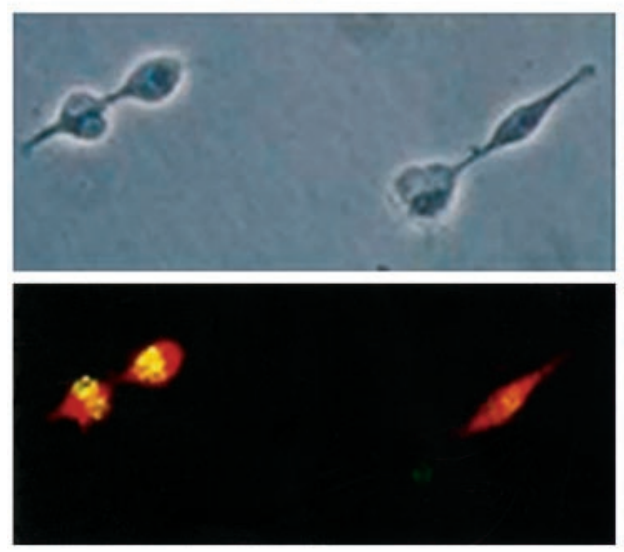

MAP - 2
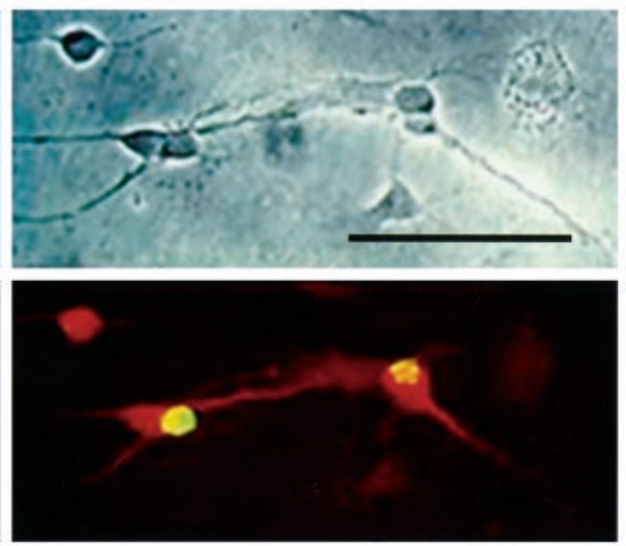

GFAP
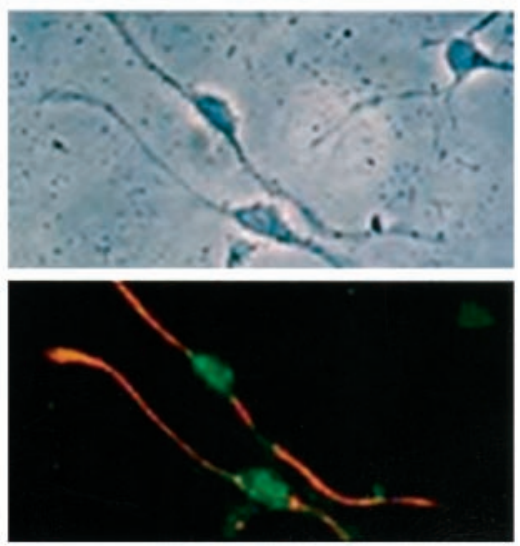

Figure 2. Top. Effects of peripheral treatment with bFGF on mitotic nuclei in the hippocampal region and SVZ on P1. Representative photographs of tissue sections from the hippocampal region $(A, B)$ or forebrain subventricular zone $(C, D)$ taken from animals treated with vehicle $(A, C)$ or bFGF $(B$, $D)$ at zero time and BrdU at $6 \mathrm{hr}$. At $8 \mathrm{hr}$ the whole brains were fixed, sectioned $(5 \mu \mathrm{m})$, and stained immunohistochemically for BrdU incorporation; black nuclei are positive, and pink nuclei are negative. bFGF treatment increased the number of BrdU-labeled cells in the hilus of the hippocampal region dentate gyrus $(B)$ and the forebrain SVZ $(D)$. Scale bars: $B(A), D(C), 100 \mu \mathrm{m}$.

Figure 4. Bottom. Potential phenotype of hippocampal cells mitotically stimulated by peripheral bFGF in P1 rats. After in vivo treatment with bFGF and BrdU, cells from the hippocampal region were isolated in culture, fixed after $48 \mathrm{hr}$, and processed for dual-fluorescent immunocytochemistry. Cells are viewed under phase (top) or dark field (bottom); cells positive for BrdU appear yellowish-green (FITC), whereas phenotypic markers are red-orange (Texas Red). After bFGF treatment, BrdU-positive nuclei were found in cells expressing the neuronal markers TuJ1 and MAP-2 and the astrocytic marker GFAP. Scale bar, $100 \mu \mathrm{m}$. 

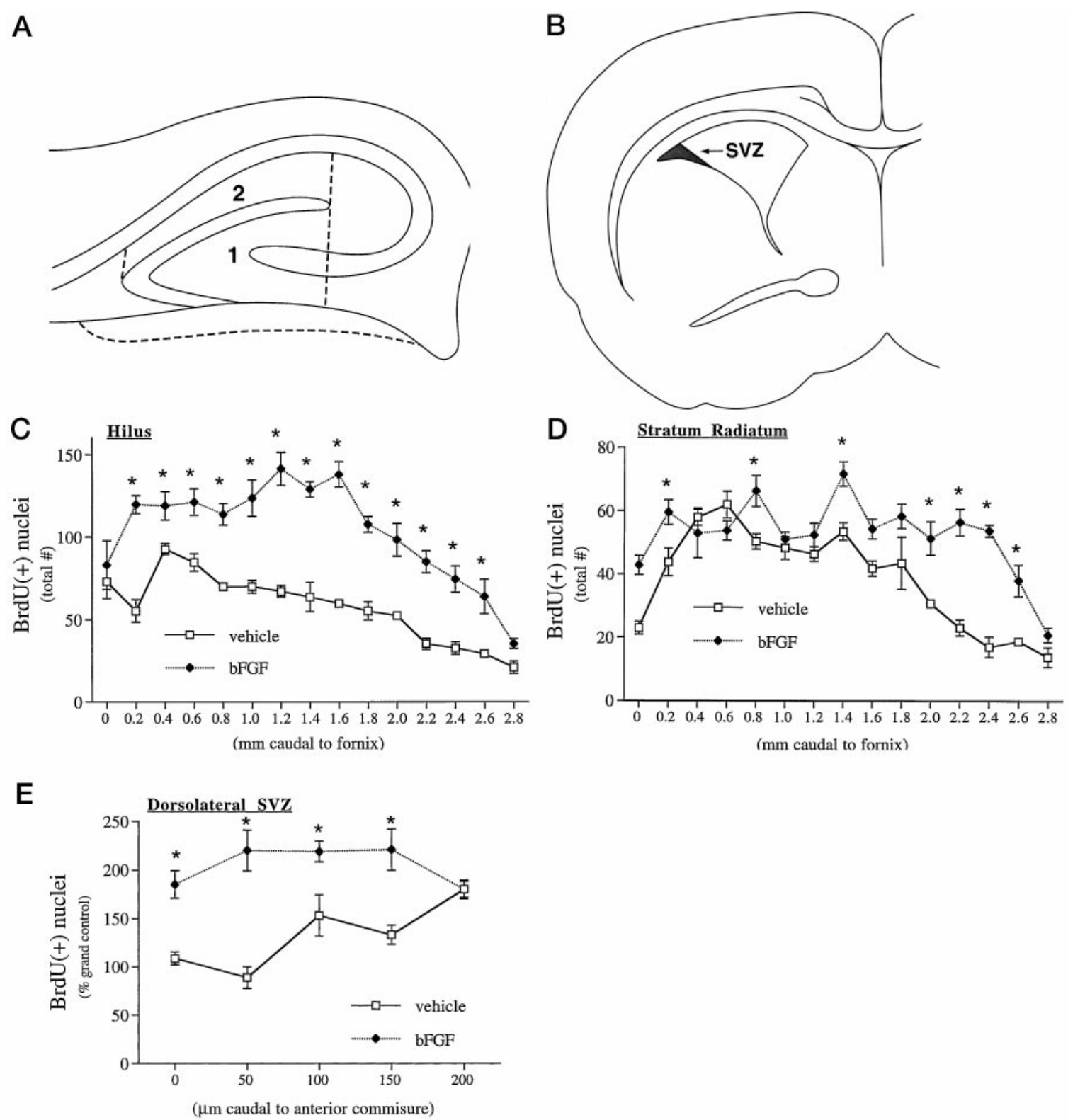

Figure 3. Quantitation of peripheral bFGF effects on mitotic nuclei in the hippocampal region and SVZ on P1. $A, B$, The total number of BrdU-positive nuclei were counted in two regions of the hippocampal formation $(A)$ and in the dorsolateral corner of the forebrain SVZ, depicted in one hemisphere (B). $C, D$, In the hippocampal formation, bFGF treatment significantly increased mitotic nuclei in both the hilus $(C ;$ region 1 in $A)$ and stratum radiatum $(D$; region 2 in $A$ ); the magnitude of the effect was dependent on anatomical position in both regions. The global effect of bFGF in the neurogenetic hilus $(67 \%)$ was significantly greater than the effect in the stratum radiatum $(22 \%)$, as determined by three-way ANOVA [significant interaction of treatment $X$ region; $\left.p<0.0001 ; F_{(1,14)}=113.1\right]$. $E$, In the forebrain SVZ, bFGF globally stimulated mitosis in the dorsolateral region 54\%, with a similar dependence of effect on anatomical gradient. Data represent mean \pm SEM from three to five sections from each of three to five animals at each region, anatomical zone, and treatment group; asterisks denote individual anatomical zones where bFGF treatment produced significant increases (attributed at $p<0.05$ ) in the number of mitotic nuclei within a given region, determined post hoc only when significant effects of "region" and "anatomical zone" were observed (this occurred in all 3 areas).

P21 (Fig. 6A), suggesting that a portion of the bFGF-responsive population present on $\mathrm{P} 1$ persists into later ages. Importantly, some animals at each of the later ages did respond at levels equivalent to that of $\mathrm{P} 1$ pups.

Because bFGF was less effective at older ages than on P1, we examined this apparent age-related decrease by measuring dose responsiveness on P14. A 20-fold higher dose of peripheral bFGF maximally stimulated DNA synthesis $65 \%$, a level equal to that measured on P1 (Fig. 6B), suggesting persistent, equivalent responsiveness of the hippocampus formation at later ages. The higher dose ensured that all animals exhibited robust responses. Significantly, the mitogenic effects of peripheral bFGF in older animals indicate that factor activity is independent of $\mathrm{BBB}$ maturity.

\section{Transfer of peripherally administered bFGF across the mature BBB}

To test the hypothesis that mitogenic effects of peripheral bFGF in older animals resulted from direct transfer of the factor across the $\mathrm{BBB}$, radioimmunoassay was performed on plasma and CSF 
A

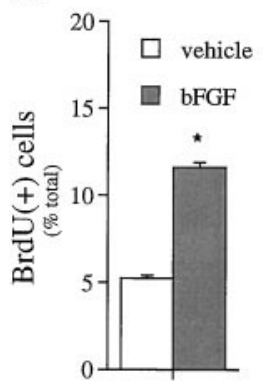

B

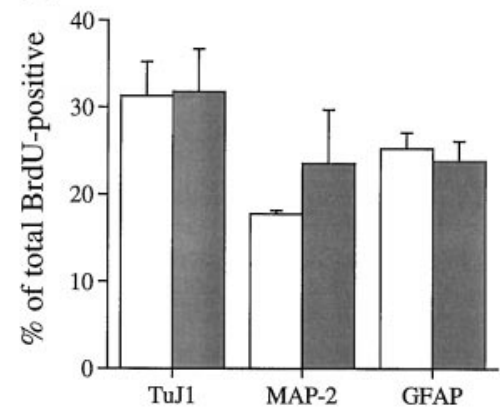

Figure 5. Effects of peripheral bFGF in vivo on the proportion and phenotypic composition of responsive cells measured in vitro. A, Peripheral bFGF treatment in vivo more than doubled the proportion of BrdUpositive cells observed in culture without affecting total cell number. $B$, Within the BrdU-positive population, however, no change in the relative proportion of neurons and astrocytes was observed. Data represent mean + SEM of at least 100 cells counted in each of four dishes in each treatment group obtained from two experiments. There was no difference in total cell numbers among groups at $48 \mathrm{hr}$ (data not shown). ${ }^{*} p<$ 0.0001, one-way ANOVA.

samples collected from mature (P28) rats treated with $500 \mathrm{ng} / \mathrm{gm}$ bFGF (Fig. 7). Significant increases in bFGF immunoreactivity were evident in both plasma and CSF compartments within $2 \mathrm{hr}$ of injection, with peak levels occurring $4 \mathrm{hr}$ after injection in both compartments. Thereafter, plasma bFGF levels decreased rapidly, with an apparent maximal half-life of $4 \mathrm{hr}$, whereas bFGF levels in CSF persisted at near maximal levels for at least $24 \mathrm{hr}$ after injection. Although $\sim 1-2 \%$ of the plasma concentration of bFGF was detected in CSF, transfer from the plasma to CSF compartment was rapid, as evidenced by parallel rates of increase in both. Thus, absorption from the subcutaneous space into the systemic circulation may be a limiting step in bioavailability. Although the kinetics of bFGF transfer is compelling, a relatively high dose was used in this experiment (500 $\mathrm{ng} / \mathrm{gm})$ to raise the bFGF signal within the range of detection of our RIA. To verify that such kinetics was relevant to experiments in which a lower factor dose was used (5-100 ng/gm), we repeated this experiment using a 25 -fold lower dose $(20 \mathrm{ng} / \mathrm{gm})$. Four hours after injection, similar CSF/blood ratios $(3.5 \%)$ of radiolabel were detected (Fig. $7 C$ ), suggesting that the pharmacokinetic distribution of bFGF after peripheral administration is conserved over the dose range of 5-500 ng/gm body weight. Furthermore, transfer of significant levels of bFGF into the brain after peripheral injection supports the contention that mitogenic effects are caused by direct action of bFGF on responsive cells in the CNS.

\section{Mitogenic effects of peripheral bFGF on neurogenetic populations of the adult}

After defining effects of bFGF in adolescent rats, we examined efficacy in adult rats (P60). At this age, all neurogenesis associated with development has ceased, while mitosis persists in precursor populations in the SVZ, olfactory tract, and hippocampal region (Altman and Bayer, 1990; Gould et al., 1992; Morshead and van der Kooy, 1992; Reynolds and Weiss, 1992; Richards et al., 1992; Lois and Alvarez-Buylla, 1993; Luskin, 1993; Kuhn et al., 1996). Peripheral bFGF increased $\left[{ }^{3} \mathrm{H}\right] \mathrm{dT}$ incorporation $20-$ $80 \%$ in homogenates of the olfactory bulb/tract and the corpus striatum SVZ. In contrast, no changes were observed in the hippocampal region or the cerebellum (Fig. 8). The restriction of effects to regions associated with persistent adult neurogenesis

(olfactory tract and SVZ) and the lack of effect in areas in which adult neurogenesis is absent (cerebellum) suggest that bFGF enhances neurogenetic mitosis.

BrdU immunohistochemistry of adult forebrain revealed that bFGF-responsive cells were specifically localized to the anterior olfactory nucleus and the immediate SVZ of the lateral ventricle (Fig. 9). The effect of bFGF was robust; although only occasional BrdU-positive cells were detected in vehicle-treated animals, large numbers of intensely positive cells were found in treated rats. Indeed, bFGF nearly tripled the number of mitotic cells in the olfactory tract and forebrain SVZ (Fig. 10). In contrast, a small number of BrdU-positive cells was noted in the subgranular zone of the dentate gyrus in vehicle-treated animals, although the number of labeled cells was unaffected by bFGF treatment (data not shown). Excluding subependyma and vasculature, few, if any, BrdU-positive cells were noted outside of these areas in either group.

\section{DISCUSSION}

Our observations indicate that peripheral bFGF stimulates DNA synthesis in multiple neurogenetic populations of the neonate, including the dentate hilus of the hippocampal region and the
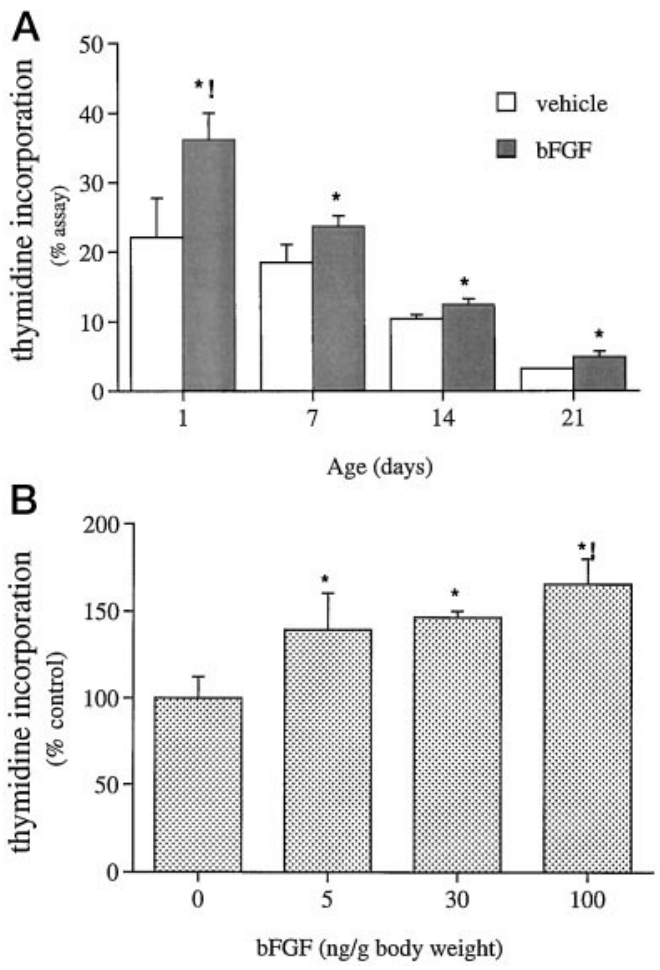

Figure 6. Effects of peripheral bFGF on hippocampal region DNA synthesis in older rats. $A$, Rats received bFGF $(5 \mathrm{ng} / \mathrm{gm})$ and $\left[{ }^{3} \mathrm{H}\right]$ thymidine $(5 \mu \mathrm{Ci} / \mathrm{gm})$ at each age. bFGF treatment increased the percent $\left[{ }^{3} \mathrm{H}\right]$ thymidine incorporation at each age [global effect of bFGF treatment by 2 -way ANOVA, $\left.{ }^{*} p<0.002 ; F_{(1,3)}=39.4\right]$; the increase observed on P1 $(65 \%)$ was significantly greater than the $25-30 \%$ increase measured at later ages (interaction of treatment $\times$ age, $! p<0.04$ ). $B$, Dose-effect curve for peripheral bFGF in the P14 hippocampal region is shown. Although each dose tested significantly increased $\left[{ }^{3} \mathrm{H}\right]$ thymidine incorporation (global effect of bFGF independent of dose, ${ }^{*} p<0.03$ ), the increase produced by $100 \mathrm{ng} / \mathrm{gm}$ bFGF $(65 \%)$ was greater than the increase produced by the lower doses [determined post hoc after significant regression of $\log ($ dose $\mathrm{bFGF}), ! p<0.02]$. Data represent mean + SEM of values obtained from three to nine animals in each treatment and age or dose group. 


\section{A Cerebrospinal Fluid}

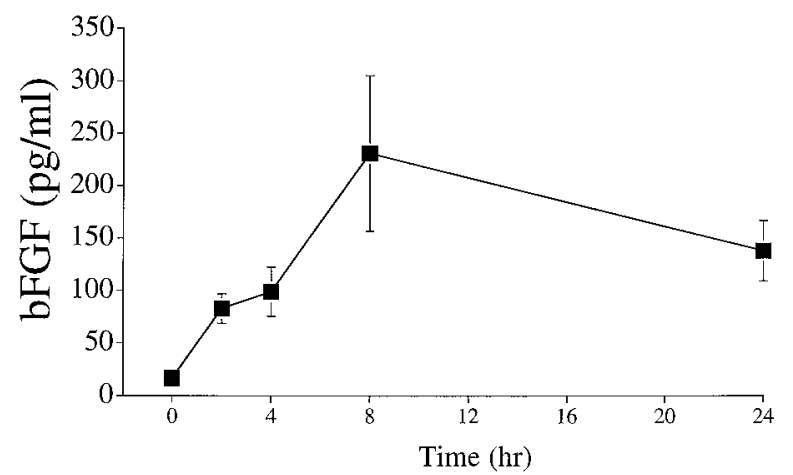

\section{B Plasma}

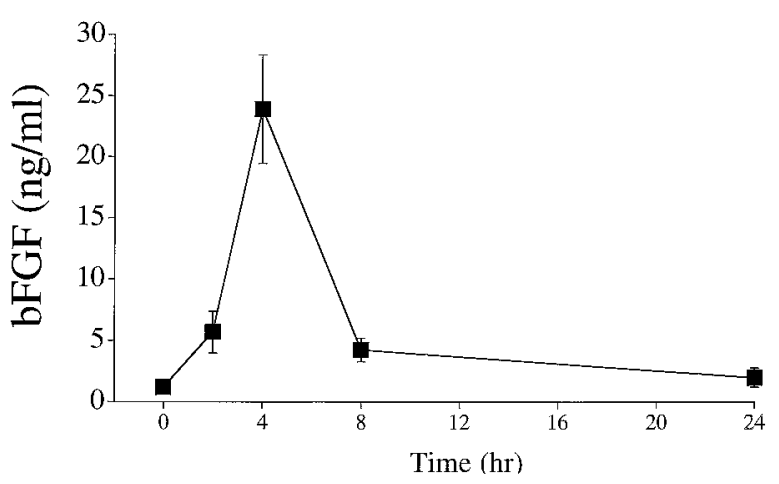

$\mathrm{C}$

\begin{tabular}{|c|c|c|c|}
\hline Animal & Blood (\%) & CSF $(\%)$ & CSF/Blood \\
\hline \hline 1 & 2.67 & 0.093 & 0.035 \\
\hline 2 & 1.38 & 0.041 & 0.030 \\
\hline \hline 3 & 1.28 & 0.051 & 0.040 \\
\hline \hline Mean & $1.78 \pm 0.4$ & $0.062 \pm 0.014$ & $0.035 \pm 0.002$ \\
\hline
\end{tabular}

Figure 7. Distribution of bFGF after subcutaneous injection. $A, B, \mathrm{P} 28$ rats received $500 \mathrm{ng} / \mathrm{gm}$ peripheral bFGF, and at given times, CSF ( $A$ ) and plasma $(B)$ were collected, and bFGF was quantitated by radioimmunoassay. Significant levels were detected 2 and 4 hr after treatment in both compartments, whereas in the CSF, significant bFGF levels persisted for $24 \mathrm{hr}$. Data represent mean \pm SEM from four to six animals at each time ( $p$ $<0.0001$ by 1 -way ANOVA). $C$, Similar kinetics was observed $4 \mathrm{hr}$ after injection of a 25 -fold lower dose of ${ }^{125} \mathrm{I}-\mathrm{bFGF}[\%=(\mathrm{cpm} / \mathrm{ml}$ sample $) /($ total cpm of ${ }^{125} \mathrm{I}-\mathrm{bFGF}$ injected/gm)].

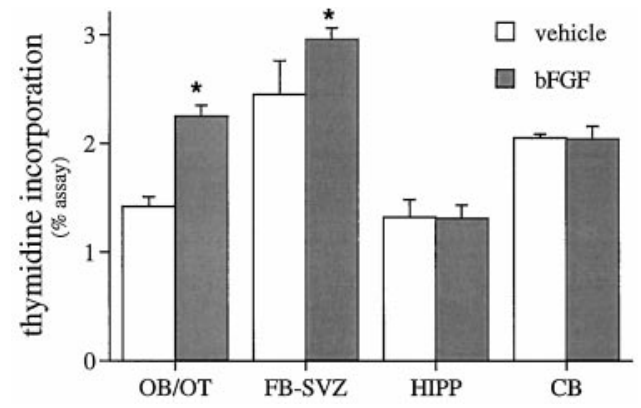

Figure 8. Effects of peripheral bFGF on DNA synthesis in multiple regions of the adult rat brain. $\mathrm{P} 60$ rats received bFGF $(100 \mathrm{ng} / \mathrm{gm})$ at zero time and $\left[{ }^{3} \mathrm{H}\right]$ thymidine $(5 \mu \mathrm{Ci} / \mathrm{gm})$ and $\mathrm{BrdU}(100 \mu \mathrm{g} / \mathrm{gm}$; Sigma $)$ at 6 $\mathrm{hr}$ and were processed at $8 \mathrm{hr}$. bFGF treatment increased the percent $\left[{ }^{3} \mathrm{H}\right]$ thymidine incorporation in homogenates of the olfactory bulb/tract $(O B / O T)$ and the forebrain SVZ $(F B-S V Z)$; no effect was observed in the hippocampal region $(H I P P)$ or the cerebellum $(C B)$. Data represent mean + SEM from three animals in each treatment group $\left({ }^{*} p<0.0001\right.$ by 1 -way ANOVA).

forebrain SVZ. The increased DNA synthesis reflects a two- to threefold increase in the number of neural precursors engaged in S-phase of the mitotic cycle, suggesting that somatic growth factors exert an ongoing influence on brain neurogenesis during development. Moreover, bFGF crossed the BBB in adults and elicited comparable increases in precursor mitosis, indicating the persistence of bFGF-responsive populations into maturity that may be regulated by peripheral signals.

\section{Populations responsive to peripheral bFGF on $\mathrm{P1}$}

Initially, the effects of peripheral bFGF on the hippocampal region and $\mathrm{SVZ}$ mitosis were defined on $\mathrm{P} 1$, when this treatment produces dramatic increases in cerebellar neuroblast mitosis (Tao et al., 1996). The near doubling in DNA synthesis produced by bFGF in both regions suggested that the factor stimulated mitosis in populations associated with neurogenesis. Indeed, immunohistochemical analysis indicated that increases in mitotic nuclei were primarily restricted to the dentate hilus in the hippocampal region and the forebrain SVZ, with little or no change observed in non-neurogenetic regions of brain.

The suggestion that peripheral bFGF stimulated neurogenetic populations on P1 was further evaluated by defining the phenotypic potential of responding cells using in vitro analysis. Although bFGF treatment in vivo doubled the percentage of mitotic cells in culture, the phenotypic composition of the proliferating population (i.e., $25 \%$ astrocytic and $25 \%$ neuronal) was unaffected by treatment. This outcome suggests one of two alternatives. Either (1) the responsive population is homogeneous and multipotential, with both neuronal and glial fates, or (2) the population is heterogeneous, consisting of multiple unipotential cells equally responsive to bFGF. bFGF reportedly stimulates both unipotential and multipotential precursors in culture, generating neurons and glia in vitro and in vivo (Kilpatrick and Bartlett, 1993, 1995; Vescovi et al., 1993; Gage et al., 1995; Gritti et al., 1996; McKay, 1997). Care must be taken in interpreting our culture analysis however, because such an in vitro approach defines the potential of the proliferating cells and not the normal fate of the cells in situ. Resolution of this issue awaits our ongoing in vivo analysis. Nonetheless, at least a portion of the responding cells exhibits neuronal potential.

\section{Peripheral bFGF increases mitosis in the adult}

The apparent selectivity of peripheral bFGF on P1 to regions associated with adult neurogenesis prompted us to examine older 


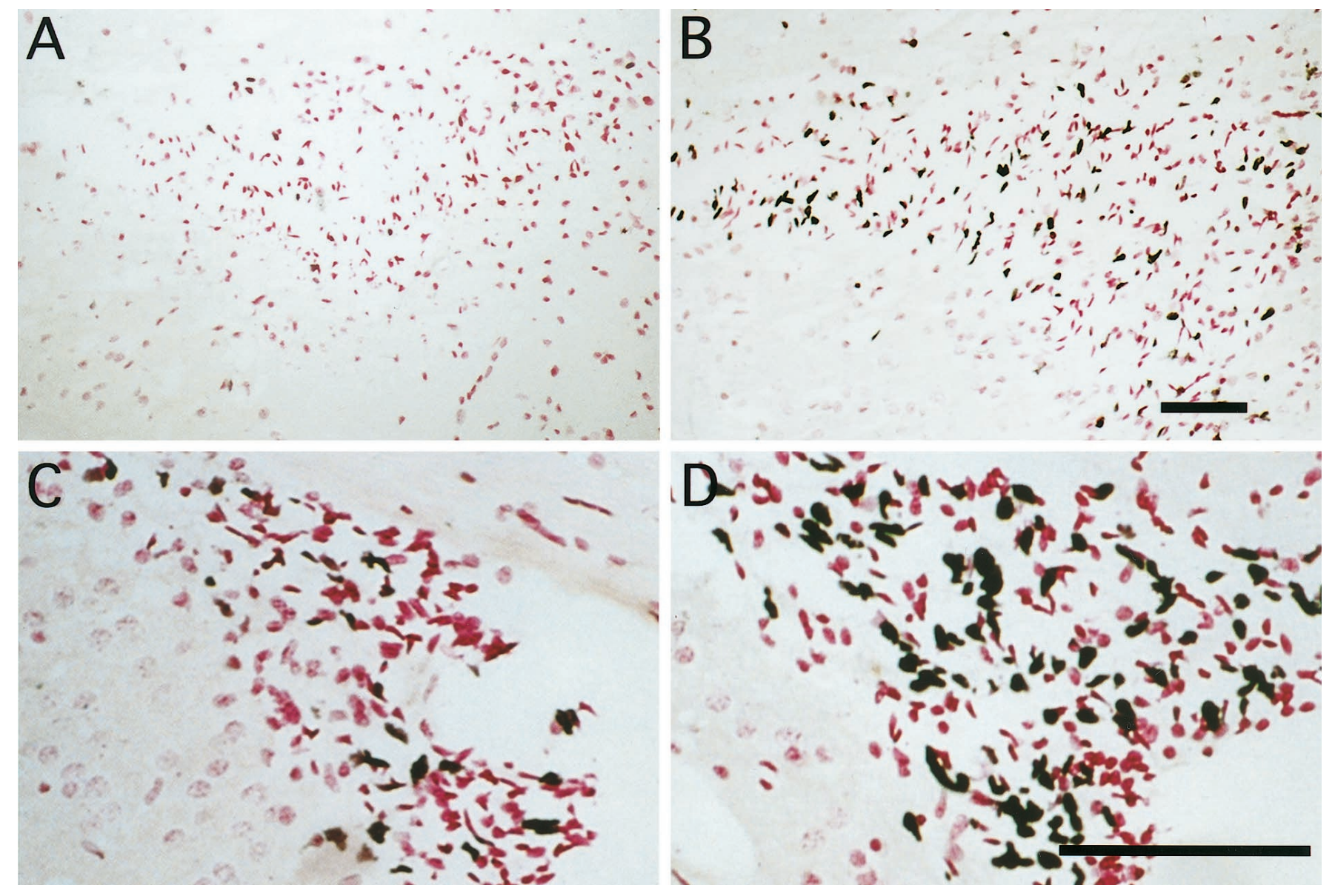

Figure 9. Effect of peripheral bFGF on mitotic nuclei in neurogenetic regions of the adult rat brain. Representative photographs of tissue sections from the anterior olfactory nucleus $(A, B)$ and the forebrain SVZ $(C, D)$ taken from adult animals treated with vehicle $(A, C)$ or with bFGF $(100 \mathrm{ng} / \mathrm{gm}$ body weight; $B, D$ ) followed by BrdU as described in Figure 8 . bFGF treatment increased the number of BrdU-labeled cells in the anterior olfactory nucleus $(B)$ and the forebrain SVZ $(D)$. Scale bars: $B(A), D(C), 100 \mu \mathrm{m}$.

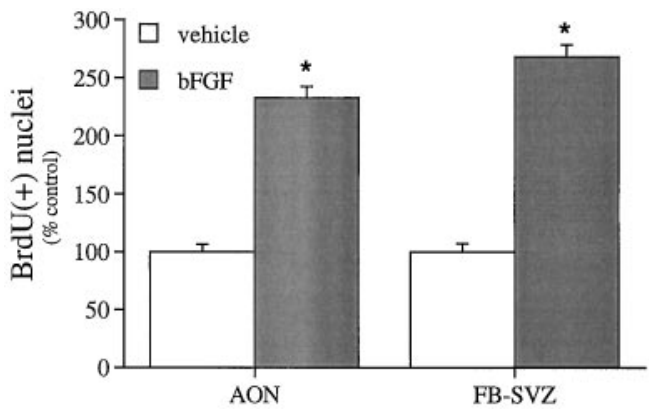

Figure 10. Quantitation of peripheral bFGF effects on mitotic nuclei within the anterior olfactory nucleus $(A O N)$ and the forebrain SVZ $(F B-S V Z)$ in adult rats. Peripheral bFGF more than doubled the number of mitotic nuclei within both regions; this effect was equivalent in both regions, and no anatomical gradient in effect was observed (3-way ANOVA; no significant interactions of region and/or anatomical zone with treatment). Data represent counts taken from at least five sections from each of three rats within each treatment group and region $\left[{ }^{*} p<\right.$ $\left.0.0001 ; F_{(1,5)}=35.7\right]$.

animals. This approach is potentially problematic; an apparent lack of effect might be attributable to multiple changes accompanying maturation, including the disappearance of responsive cells from a region, or simply exclusion of bFGF by the maturing $\mathrm{BBB}$ (or both). To distinguish between these two possibilities, we tested the factor at various ages (P7-P21). Remarkably, peripheral bFGF stimulated mitosis at all ages to a similar degree, suggesting that the bFGF-responsive population(s) persists beyond early development and that the factor can act on this population across the mature BBB. The efficacy of peripheral bFGF in adult animals with a mature BBB suggested two possible mechanisms for bFGF action: indirect activity, in which bFGF induces secondary mitogenic signals from the vascular side of the $\mathrm{BBB}$, or direct activity, in which bFGF itself crosses the BBB to access responsive cells. The pharmacokinetic analyses, demonstrating rapid and significant transfer of bFGF across the mature $\mathrm{BBB}$, favor a direct action of peripheral bFGF on responsive populations, although actions mediated by other cells cannot be excluded. Future studies may define FGF receptor expression by mitotic precursors and rapid activation of intracellular signaling after ligand exposure.

Consistent with findings in the neonate, effects of the factor in the adult were restricted to regions associated with persistent neurogenesis. Furthermore, the parallel effects of bFGF on the SVZ of both neonates and adults suggest that these populations are related, because factors regulating neurogenesis during development may act similarly in the adult, as recently proposed (Weiss et al., 1996; McKay, 1997). This view is complicated by the apparent lack of bFGF effects in the adult hippocampal region, where neurogenesis persists into adulthood. This ineffectiveness 
may represent a genuine loss of bFGF-responsive precursors within the adult hippocampal region; alternatively, responsive cells may be present, but mitosis may have been undetected because of changes in cycle kinetics (e.g., increased cell cycle length), the size of the responsive population relative to nonproliferating cells, or factor access. We favor the first explanation, because (1) SVZ responses in the adult were clear and robust, (2) ongoing studies using more direct and extended factor application confirm adult hippocampal region unresponsiveness to bFGF (Kuhn et al., 1997), and (3) hippocampal region precursors do respond to local infusions of epidermal growth factor (P. Tanapat and E. Gould, personal communication). In addition, different precursor pools proliferate in the dentate gyrus as a function of age; during the first postnatal month, precursors are derived from the first and second dentate migrations, whereas after P30, precursors localize to the subgranular zone specifically (Altman and Bayer, 1990), raising the possibility that different signals regulate functionally distinct precursor populations. It should be noted, however, that the sensitivity of the assays used to detect mitosis limit any conclusion regarding the specificity of bFGF on selected neurogenetic populations. Indeed, the detection of low absolute differences, particularly in thymidine incorporation experiments, could reflect high relative differences in proliferation of small or diffuse neurogenetic populations in other brain regions. The cellular bases for such regional differences in bFGF responsiveness are being further characterized in our laboratory.

\section{Possible mechanisms and implications of bFGF effects}

If peripheral bFGF is capable of producing large, rapid increases in mitosis in multiple neurogenetic populations, then to what extent is proliferation of these cells regulated by brain levels of bFGF? Previous studies indicated that during early development, bFGF potently regulates neurogenesis; intraventricular treatment with anti-bFGF antibodies massively $(>50 \%)$ decreases DNA synthesis in both the cerebellum and the hippocampal region (Tao et al., 1997). The source of this bFGF is unclear. However, increasing evidence suggests that the factor may be acting at sites distant from its source. Significant levels of bioactive bFGF have been detected in both plasma and CSF (Baird, 1994; present study); furthermore, a soluble, extracellular domain of the FGF receptor has been detected in both compartments (Hanneken et al., 1995), suggesting molecular mechanisms to stabilize factor levels. These findings, combined with the robust effects of peripheral bFGF, suggest that extracellular bFGF, synthesized in the brain (Emoto et al., 1989; Caday et al., 1990; Giordano et al., 1992; Woodward et al., 1992; El-Husseini et al., 1994) or derived from somatic sources (Gonzalez et al., 1990; Biegler et al., 1995), influences developmental and mature neural proliferation (Unsicker et al., 1993; Baird, 1994). Potentially, somatic bFGF may act across the $\mathrm{BBB}$ to coordinate brain neuronal numbers with the requirements of peripheral tissue mass (Purves, 1988; Oppenheim, 1991). More generally, it is likely that peripheral signals interact with local brain factors during neurogenesis, balancing regional ontogenetic programs with organismic endocrine status (Legrand, 1977; Bohn and Lauder, 1978; Gould et al., 1992; Neveu and Arenas, 1996).

The central effects of peripheral bFGF in the adult brain may also be relevant to evidence of experience-dependent changes in neurogenesis. Recent studies indicate that neurogenesis in the adult dentate gyrus is differentially regulated by environment, learning, and stress. By altering precursor proliferation and/or survival, complex environment, running, and learning have been shown to increase neurogenesis (Gould et al., 1999; van Praag et al., 1999). Conversely, environmental stress negatively regulates precursor proliferation, via action of adrenal steroids and NMDA receptor activation (Gould et al., 1992, 1997; Cameron et al., 1995, 1998). Potentially, bFGF released into the periphery from muscle or adrenal medulla during exercise and stress may participate in experience-dependent neurogenesis (Gonzalez et al., 1990; Biegler et al., 1995; Breen et al., 1996; Cottone et al., 1998). One may speculate, for example, that activity-induced release of peripheral bFGF increases brain SVZ mitosis, whereas concomitant adrenal steroid secretion blocks proliferative effects in the dentate gyrus. Studies on the long-term effects of increased somatic bFGF may help clarify potential roles of the factor in interactions among activity, learning, and adult neurogenesis (Greenough et al., 1999).

In addition to novel ontogenetic and behavioral functions, our evidence of a physiological pathway transporting peripheral growth factors to the adult CNS has therapeutic implications. Growth factor administration may be useful in treating progressive neurological disease and acute injuries, such as stroke and trauma, by slowing damage, rescuing injured neurons, or promoting recovery (Hefti, 1994; Kawamata et al., 1997). In addition, recent studies raise the possibility of generating replacement neurons by stimulating endogenous precursor proliferation (Cameron et al., 1995; Craig et al., 1996; Weiss et al., 1996; Kuhn et al., 1997; McKay, 1997; Gage, 1998). Although most approaches to human therapy consider intracerebroventricular growth factor administration, invasive surgical procedures could be circumvented by effective peripheral strategies. In fact, animal studies, demonstrating the efficacy of peripheral bFGF in preventing tissue damage and promoting recovery from hypoxicischemic and excitotoxic insults (Fisher et al., 1995; Kirschner et al., 1995; Bethel et al., 1997), formed the basis of the ongoing human clinical trial of intravenous bFGF for acute stroke (S. Finklestein, personal communication) (Kawamata et al., 1997). However, contrary to a model in which peripheral bFGF accessed the brain only locally through the acutely damaged BBB (Fisher et al., 1995; Kirschner et al., 1995), our observations suggest an ongoing physiological transfer, which is not restricted spatially or temporally. Potentially, we may take advantage of this pathway to deliver bFGF to the CNS, where it may serve as a neurotrophic factor or regulator of endogenous precursor proliferation, ultimately influencing the clinical course of brain dysfunction. Finally, although underlying mechanisms remain to be defined, the novel transfer of bFGF may also be exploited to transport other bioactive molecules across the $\mathrm{BBB}$ as therapies for neuronal diseases.

\section{REFERENCES}

Altman J, Bayer SA (1990) Migration and distribution of two populations of hippocampal granule cell precursors during the perinatal and postnatal period. J Comp Neurol 301:365-381.

Baird A (1994) Fibroblast growth factors: activities and significance of non-neurotrophin neurotrophic growth factors. Curr Opin Neurobiol 4:78-86.

Bethel A, Kirsch JR, Koehler RC, Finklestein SP, Traystman RJ (1997) Intravenous basic fibroblast growth factor decreases brain injury resulting from focal ischemia in cats. Stroke 28:609-615.

Biegler SC, Henkel AW, Unsicker K (1995) Localization of basic fibroblast growth factor in bovine adrenal chromaffin cells. J Neurochem 64:1521-1527.

Bohn MC, Lauder JM (1978) The effects of neonatal hydrocortisone on rat cerebellar development. Dev Neurosci 1:250-266. 
Breen EC, Johnson EC, Wagner H, Tseng HM, Sung L, Wagner PD (1996) Angiogenic growth factor mRNA responses in muscle to a single bout of exercise. J Appl Physiol 81:355-361.

Caday CG, Klagsburn M, Fanning PJ, Mirzabegian A, Finklestein SP (1990) Fibroblast growth factor levels in the developing rat brain. Dev Brain Res 52:241-246.

Cameron HA, McEwen BS, Gould E (1995) Regulation of adult neurogenesis by excitatory input and activation of NMDA receptor activation in the dentate gyrus. J Neurosci 15:4687-4692.

Cameron HA, Tanapat P, Gould E (1998) Adrenal steroids and $N$-methyl-D-aspartate receptor activation regulate neurogenesis in the dentate gyrus of adult rats through a common pathway. Neuroscience $82: 349-354$.

Carr VM, Simpson SB (1978) Proliferative and degenerative events in the early development of chick dorsal root ganglia. II. Responses to altered peripheral fields. J Comp Neurol 182:741-755.

Coggeshall RE, Lekan HA (1996) Methods for determining numbers of cells and synapses. J Comp Neurol 364:6-15.

Cottone S, Vella MC, Vadala A, Neri AL, Riccobene R, Cerasola G (1998) Influence of vascular load on plasma endothelin-1, cytokines and catecholamine levels in essential hypertensives. Blood Press $7: 144-148$.

Craig CG, Tropepe V, Morshead CM, Reynolds BA, Weiss S, van der Kooy D (1996) In vivo growth factor expansion of endogenous subependymal neural precursor cell populations in the adult mouse brain. J Neurosci 16:2649-2658.

DiCicco-Bloom E, Black IB (1988) Insulin growth factors regulate the mitotic cycle in cultured rat sympathetic neuroblasts. Proc Natl Acad Sci USA 85:4066-4070.

DiCicco-Bloom E, Black IB (1989) Depolarization and insulin-like growth factor-I (IGF-I) differentially regulate the mitotic cycle in cultured rat sympathetic neuroblasts. Brain Res 491:403-406.

DiCicco-Bloom E, Townes-Anderson E, Black IB (1990) Neuroblast mitosis in dissociated culture: regulation and relationship to differentiation. J Cell Biol 110:2073-2086.

DiCicco-Bloom EM, Friedman WJ, Black IB (1993) NT3 stimulates sympathetic neuroblast proliferation by promoting precursor survival. Neuron 11:1101-1111.

Drago J, Murphy M, Carroll SM, Harvey RP, Bartlett PF (1991) Fibroblast growth factor-mediated proliferation of central nervous system precursors depends on endogenous production of insulin-like growth factor I. Proc Natl Acad Sci USA 88:2199-2203.

El-Husseini AE, Patersin JA, Shiu RP (1994) Basic fibroblast growth factor (BFGF) and two of its receptors, FGFR1 and FGFR2: gene expression in the rat brain during postnatal developmental as determined by quantitative RT-PCR. Mol Cell Endocrinol 104:191-200.

ElShamy WM, Linnarsson S, Lee K-F, Jaenisch R, Ernfors P (1996) Prenatal and postnatal requirements of NT-3 for sympathetic neuroblast survival and target innervation of specific targets. Development 122:491-500.

Emoto N, Gonzalez A-M, Walicke PA, Wada E, Simmons DM, Shimasaki S, Baird A (1989) Basic fibroblast growth factor (FGF) in the central nervous system: identification of specific loci of basic FGF expression in the rat brain. Growth Factors 2:21-29.

Fayein N, Courtois Y, Jeanny J (1992) Basic fibroblast growth factor high and low affinity binding sites in developing mouse brain, hippocampus and cerebellum. Biol Cell 76:1-13.

Fisher M, Meadows ME, Do T, Charette M, Finklestein SP (1995) Delayed treatment with intravenous basic fibroblast growth factor reduces infarc size following permanent focal cerebral ischemia in rats. J Cereb Blood Flow Metab 15:573-584.

Gage FH (1998) Cell therapy. Nature 392[Suppl]:18-24.

Gage FH, Coates PW, Palmer TD, Kuhn HG, Fisher LJ, Suhonen JO, Peterson DA, Suhr ST, Ray J (1995) Survival and differentiation of adult neuronal progenitor cells transplanted to the adult brain. Proc Natl Acad Sci USA 92:11879-11883.

Gao W, Heintz N, Hatten ME (1991) Cerebellar granule cell neurogenesis is regulated by cell-cell interaction in vitro. Neuron 6:705-715.

Gensburger C, Labourdette G, Sensenbrenner M (1987) Brain basic fibroblast growth factor stimulates the proliferation of rat neuronal precursor cells in vitro. FEBS Lett 217:1-5.

Giordano S, Sherman L, Lyman W, Morrison R (1992) Multiple molecular weight forms of basic fibroblast growth factor are developmentally regulated in the central nervous system. Dev Biol 152:293-303.
Gonzalez A-M, Buscaglia M, Ong M, Baird A (1990) Distribution of basic fibroblast growth factor in the 18-day rat fetus: localization in the basement membrane of diverse tissues. J Cell Biol 110:753-765.

Gould E, Cameron HA, Daniels DC, Woolley CS, McEwen BS (1992) Adrenal hormones suppress cell division in the adult rat dentate gyrus. J Neurosci 12:3642-3650.

Gould E, McEwen BS, Tanapat P, Galea IAM, Fuchs E (1997) Neurogenesis in the dentate gyrus of the adult tree shrew is regulated by psychosocial stress and NMDA receptor activation. J Neurosci 17:2492-2498.

Gould E, Beylin A, Tanapat P, Reeves A, Shors TJ (1999) Learning enhances adult neurogenesis in the hippocampal formation. Nat Neurosci 2:260-265.

Greenough WT, Cohen NJ, Juraska JM (1999) New neurons in old brains: learning to survive? Nat Neurosci 2:203-205.

Gritti A, Parati EA, Cova L, Frolichsthal P, Galli R, Wanke E, Faravelli L, Morassutti DJ, Roisen F, Nickel DD, Vescovi AL (1996) Multipotential stem cells from the adult brain proliferate and self renew in response to basic fibroblast growth factor. J Neurosci 16:1091-1100.

Hanneken A, Frautschy S, Galasko D, Baird A (1995) A fibroblast growth factor binding protein in human cerebral spinal fluid. NeuroReport 6:886-888.

Hefti F (1994) Neurotrophic factor therapy for nervous system degenerative diseases. J Neurobiol 25:1418-1435.

Hollyday M, Hamburger V (1976) Reduction of the naturally occurring motor neuron loss by enlargement of the periphery. J Comp Neurol 170:311-320.

Kawamata T, Speliotes EK, Finklestein SP (1997) The role of polypeptide growth factors in recovery from stroke. Adv Neurol 73:377-382.

Kilpatrick TJ, Bartlett PF (1993) Cloning and growth of multipotential neural precursors: requirements for proliferation and differentiation. Neuron 10:255-265.

Kilpatrick TJ, Bartlett PF (1995) Cloned multipotential precursors from the mouse cerebrum require FGF-2, whereas glial restricted precursors are stimulated with either FGF-2 or EGF. J Neurosci 15:3653-3661.

Kirschner PB, Henshaw R, Weise J, Trubetskoy V, Finklestein SP, Schulz JB, Beal MF (1995) Basic fibroblast growth factor protects against excitotoxicity and chemical hypoxia in both neonatal and adult rats. J Cereb Blood Flow Metab 15:619-623.

Kuhn HG, Dickinson-Anson H, Gage FH (1996) Neurogenesis in the dentate gyrus of the adult rat: age-related decrease of neuronal progenitor proliferation. J Neurosci 16:2027-2033.

Kuhn HG, Winkler J, Kempermann G, Thal LJ, Gage FH (1997) Epidermal growth factor and fibroblast growth factor-2 have different effects on neural progenitors in the adult rat brain. J Neurosci $17: 5820-5829$.

Legrand J (1977) Morphologic and biochemical effects of hormones on the developing nervous system in mammals. In: Brain: fetal and infant (Berenberg SR, ed), pp 137-164. The Hague, Netherlands: Martinus Nijhoff Medical.

Lois C, Alvarez-Buylla A (1993) Proliferating subventricular zone cells in the adult mammalian forebrain can differentiate into neurons and glia. Proc Natl Acad Sci USA 90:2074-2077.

Lois C, Alvarez-Buylla A (1994) Long-distance neuronal migration in the adult mammalian brain. Science 264:1145-1148.

Luskin MB (1993) Restricted proliferation and migration of postnatally generated neurons derived from the forebrain subventricular zone. Neuron 11:173-189.

McKay R (1997) Stem cells in the central nervous system. Science 276:66-71.

Morshead CM, van der Kooy D (1992) Postmitotic death is the fate of constitutively proliferating cells in the subependymal layer of the adult mouse brain. J Neurosci 12:249-256.

Neveu I, Arenas E (1996) Neurotrophins promote the survival and development of neurons in the cerebellum of hypothyroid rats in vivo. J Cell Biol 133:631-646.

Oppenheim RW (1991) Cell death during development of the nervous system. Annu Rev Neurosci 14:453-501.

Pincus DW, DiCicco-Bloom E, Black IB (1990) Vasoactive intestinal peptide regulates mitosis, differentiation and survival of cultured sympathetic neuroblasts. Nature 343:564-567.

Pincus DW, DiCicco-Bloom E, Black IB (1994) Trophic mechanisms regulate mitotic neuronal precursors: role of vasoactive intestinal peptide (VIP). Brain Res 663:51-60. 
Prestige MC (1967) The control of cell number in the lumbar ventral horns during the development of Xenopus laevis tadpoles. J Embryol Exp Morphol 18:359-387.

Purves D (1988) Body and brain, a trophic theory of neural connections. Cambridge, MA: Harvard UP.

Ray J, Peterson DA, Schinstine M, Gage FH (1993) Proliferation, differentiation, and long-term culture of primary hippocampal neurons. Proc Natl Acad Sci USA 90:3602-3606.

Reynolds BA, Weiss S (1992) Generation of neurons and astrocytes from isolated cells of the adult mammalian central nervous system. Science 255:1707-1710.

Richards LJ, Kilpatrick TJ, Bartlett PF (1992) De novo generation of neuronal cells from the adult mouse brain. Proc Natl Acad Sci USA 89:8591-8595.

Tao Y, Black IB, DiCicco-Bloom E (1996) Neurogenesis in neonatal rat brain is regulated by peripheral injection of basic fibroblast growth factor (bFGF). J Comp Neurol 376:653-663.

Tao Y, Black IB, DiCicco-Bloom E (1997) In vivo neurogenesis is inhibited by neutralizing antibodies to basic fibroblast growth factor (bFGF). J Neurobiol 33:289-296.

Unsicker K, Grothe C, Ludecke G, Otto D, Westermann R (1993) Fibroblast growth factors: their roles in the central and peripheral nervous system. In: Neurotrophic factors (Loughlin SE, Fallon JH, eds), pp 312-338. New York: Academic.

van Praag H, Kempermann G, Gage FH (1999) Running increases cell proliferation in the adult mouse dentate gyrus. Nat Neurosci 2:266-270.

Vescovi AL, Reynolds BA, Fraser DD, Weiss S (1993) bFGF regulates the proliferative fate of unipotent (neuronal) and bipotent (neuronal/ astroglial) EGF-generated CNS progenitor cells. Neuron 11:951-966.

Vicario-Abejon C, Johe KK, Hazel TG, Collazo D, McKay RDG (1995) Functions of basic fibroblast growth factor and neurotrophins in the differentiation of hippocampal neurons. Neuron 15:105-114.

Wanaka A, Milbrandt J, Johnson Jr EM (1991) Expression of FGF receptor gene in rat development. Development 111:455-468.

Weiss S, Reynolds BA, Vescovi AL, Morshead CM, Craig CG, van der Kooy D (1996) Is there a neural stem cell in the mammalian forebrain? Trends Neurosci 19:387-393.

Woodward WR, Nishi R, Meshul CK, Williams TE, Coulombe M, Eckenstein FP (1992) Nuclear and cytoplasmic localization of basic fibroblast growth factor in astrocytes and CA2 hippocampal neurons. J Neurosci 12:142-152.

Yaginuma H, Tomita M, Takashita N, McKay SE, Cardwell C, Yin Q-W, Oppenheim RW (1996) A novel type of programmed neuronal death in the cervical spinal cord of the chick embryo. J Neurosci 16:36853703. 